\title{
O QUE SABEMOS SOBRE AS AMEBAS DE VIDA LIVRE ATÉ O MOMENTO?
}

WHAT WE KNOW ABOUT FREE-LIVING AMOEBA SO FAR?

\section{Poliana Lucena Nunes (LUCENA-NUNES, P.)}

Doutora em Medicina Tropical e Infectologia. Curso de Farmácia. Faculdade Evangélica de Ceres, Ceres-GO, Brasil. polianalucena1@gmail.com

\section{Endereço para correspondência:}

Av. Brasil, s/ n., setor Morada Verde, Ceres-GO. Brasil. CEP: 76300-000. Fone: (62) 33231040. E-mail: polianalucena1@gmail.com

\section{RESUMO}

Introdução: Bactérias, vírus, fungos, protozoários e helmintos têm sido associados a infecções humanas em locais de assistência à saúde. Dentre eles: Naegleria fowleri, Balamuthia mandrillaris, Sappinia pedata e algumas espécies de Acanthamoeba spp. constituem o grupo das Amebas de Vida Livre (AVL) que podem causar doença grave no SNC, pele, órgãos internos e olhos. Objetivo: Estabelecer as principais características biológicas, clínicas e propedêuticas das infecções por AVL em humanos por meio de pesquisa literária. Metodologia: Foi realizada uma revisão de literatura do tipo narrativa a partir de artigos publicados em língua inglesa e portuguesa entre 2010 e 2020 nas bases científicas Scielo e Pubmed. A busca pelas produções científicas se deu a partir dos descritores DECS e MESH. Resultados e discussão: Acanthamoeba spp. e B. mandrillaris podem causar encefalite amebiana granulomatosa que é mais comum em imunodeprimidos. Enquanto, a meningoencefalite amebiana primária por $N$. fowleri atinge principalmente jovens adultos saudáveis com evolução rapidamente fatal em 7 dias do aparecimento dos sintomas. Para $S$. pedata a encefalite descrita ocorreu em imunocompetente, mas há apenas um caso relatado até o presente momento. Além disso, em imunocompetentes usuários de lentes de contato podem ocorrer ceratite amebiana por Acanthamoeba spp. O sítio de infecção por AVL é bastante diversificado e os sintomas observados são inespecíficos e similares a patógenos mais rotineiros nos ambientes hospitalares. Isso dificulta a suspeita clínica. Não há um esquema terapêutico específico, apesar de o diagnóstico precoce favorecer a diminuição de morbimortalidade. Conclusão: A complexidade da biologia, clínica e propedêutica das infecções causadas por AVL provavelmente está associada a uma subnotificação dos casos, os quais apesar de raros possuem altos índices de morbimortalidade, inferindo a necessidade de maior divulgação deste tema junto à sociedade.

Palavras-chaves: Amebas de Vida Livre. Potencial patogênico. Imunocompetentes. Imunocomprometidos.

\section{ABSTRACT}


Introduction: Bacteria, viruses, fungi, protozoa and helminths have been associated with human infections in health care sites. The Free-Living Amoebae (FLA), including Naegleria fowleri, Balamuthia mandrillaris, Sappinia pedata and some species of Acanthamoeba spp., can cause severe disease in the CNS, skin, internal organs and eyes of humans. Objective: To establish the main biological, clinical and propaedeutic characteristics of AVL infections in humans through literary research. Methodology: A literature review of the narrative type was carried out published in English and Portuguese between 2010 and 2020 in the scientific databases Scielo and Pubmed. The search for scientific productions took place from the descriptors DECS and MESH. Results and discussion: Acanthamoeba spp. and $B$. mandrillaris may cause granulomatous amoebic encephalitis is more common in immunosuppressed patients. Meanwhile, primary amoebic meningoenecephaly by $N$. fowleri mainly affects healthy young adults with rapidly fatal evolution in 7 days of the onset of symptons. For $S$. pedata the described encephalitis occurred in immunocompetent, but there is only one case reported to date. In addition, in immunocompetent contact lens wearers, amoebic keratitis may occur by Acanthamoeba spp. The site of AVL infection is quite diverse and the symptoms observed are nonspecific and similar to more routine pathogens in hospital settings. This makes clinical suspicion difficult. There is no specific therapeutic regimen, although early diagnosis favors the reduction of morbidity and mortality. Conclusion: The complexity of the biology, clinical and propaedeutics of infections caused by AVL is probably associated with underreporting of cases, despite high rates of morbidity and mortality, inferring the need for greater dissemination to society.

Keywords: Free Living Amoebae. Pathogenic potential. Immunocompetent. Immunocompromised.

\section{INTRODUÇÃO}

Amebas de Vida Livre (AVL) constituem um grupo de quatro gêneros incluindo Acanthamoeba spp., Naegleria fowleri, Balamuthia mandrillaris e Sappinia pedata que apresentam elevado potencial patogênico acometendo seres humanos e animais. São considerados parasitos facultativos, ou seja, podem utilizar ou não um hospedeiro vertebrado em seu ciclo biológico (CALIXTO et al., 2014; WALOCHNIK, 2014; KRÓL-TURMINSKA; OLENDER, 2017).

Para muitos autores essas amebas se encontram em transição para a vida parasitária. Elas participam da reciclagem ambiental da água e do solo utilizando bactérias, vírus e alguns eucariotos como substrato alimentar. Com isso, as AVL podem ser isoladas de uma ampla variedade de ambientes, incluindo a água, o solo, a poeira e o ar, sendo facilmente detectadas nos meses quentes do ano (WALOCHNIK, 2014; BALCZUN; SCHEID, 2017; LARESJIMÉNEZ et al., 2018; LONG et al., 2018).

As fontes de isolamento são diversas, essas amebas já foram descritas em água mineral engarrafada e de nascentes, torneiras, piscinas, sistemas de água quente, filtros de retorno, ambientes domésticos, biofilmes, instrumentos dentários e de hemodiálise, lentes de contato e suas soluções de limpeza, unidades de ar-condicionado, esgoto e até mesmo de secreções de 
orofaringe, conjuntiva ocular, lesões na pele, SNC e urina de seres humanos (MARCIANOCABRAL; JAMERSON; KANESHIRO, 2010; BALCZUN; SCHEID, 2017; LARESJIMÉNEZ et al., 2018; ÜSTÜNTÜRK-ONAN; WALOCHNIK, 2018).

As manifestações clínicas não raramente se relacionam com o estado imunológico do paciente sendo descritos casos de ceratite amebiana, encefalite amebiana granulomatosa, meningoencefalite e lesões em pele e órgãos internos. Acanthamoeba spp., N. fowleri, B. mandrillaris e $S$. pedata se relacionam ao acometimento neurológico sendo a via respiratória uma importante forma de contágio. Já a ceratite amebiana está relacionada principalmente a Acanthamoeba spp. e o uso de lentes de contato (VISVESVARA, 2010; PINNA et al., 2017).

Os sintomas gerados pelas infecções por AVL são inespecíficos e podem ser confundidos com aqueles produzidos por vírus, bactérias, fungos e protozoários, o que dificulta a suspeita clínica nos consultórios médicos. Além disso, as técnicas laboratoriais específicas para o diagnóstico dessas amebas são pouco executadas, dificultando a sua detecção laboratorial. Em geral, as infecções por AVL são tidas como raras (VISVESVARA, 2010; NIYYATI; LASGERDI; LORENZO-MORALES, 2015).

Sobre o tratamento, os cistos apresentam dupla ou tripla parede celular, a qual é altamente resistente aos diversos fármacos disponíveis. Não há um protocolo padrão e os medicamentos convencionalmente empregados para outros patógenos não tem ação efetiva sobre as AVL. Isto aliado à alta agressividade dessas amebas resulta em elevados índices de morbimortalidade. Na maioria dos casos descritos, o diagnóstico foi dado no post-mortem da infecção neurológica ou após causar cegueira (WALOCHNIK, 2014; CARRIJOCARVALHO et al., 2019; BAIG, 2019).

Esses dados demonstram a necessidade de maior investigação das infecções por AVL dada a complexidade dos aspectos biológicos, clínicos, diagnósticos e terapêuticos relacionados a essas amebas. Com isso, o objetivo desta pesquisa foi revisar as principais características biológicas, clínicas e propedêuticas das infecções causadas por Acanthamoeba spp., Naegleria fowleri, Balamuthia mandrillaris e Sappinia pedata.

\section{METODOLOGIA}

Foi realizada uma revisão bibliográfica do tipo narrativa para analisar os principais fatores associados à ocorrência de infecções por Amebas de Vida Livre (AVL). A pesquisa literária foi realizada nos meses de julho e agosto de 2019 por uma pesquisadora. Foi realizada a delimitação do tema de interesse, dos critérios de inclusão e exclusão, as estratégias de busca e seleção. Para coleta e seleção dos artigos científicos foram consultados: 
o Scientific Eletronic Library Online (SCIELO) e o National Center for Biotechnology Information (NCBI), via U.S. National Library of Medicine (PUBMED). Foram incluídos artigos publicados em língua portuguesa e inglesa no período de 2010 a 2020. A busca pelas produções científicas se deu a partir de Descritores em Ciências da Saúde (DECS) e Medical Subject Headings (MESH).

Para cada estudo incluído foram extraídos: autor, periódico, ano de publicação, tipo de estudo, objetivo e principais resultados. Para a plataforma SCIELO foi adotada a DECS por meio da locução “(Amebas de Vida Livre) AND (Infecção humana) AND (Acanthamoeba spp.) AND (Naegleria fowleri) AND (Balamuthia mandrillaris) OR (Sappinia pedata)" foi adotada. Da mesma forma, na plataforma PUBMED adotou-se o uso de MESH, (Free-living Amoebae) AND (Acanthamoeba spp.) AND (Naegleria fowleri) AND (Balamuthia mandrillaris) OR (Sappinia pedata) AND (Human Infection).

Também foram consultadas as referências dos artigos incluídos, para agrupar o maior número de artigos sobre o tema. As duplicatas encontradas durante a busca foram eliminadas manualmente. Visando a objetividade na exposição do conteúdo produzido, o papel de cada uma das quatro espécies de Amebas de Vida Livre foi apresentado e discutido em subtópicos.

\section{RESULTADOS E DISCUSSÃO}

Foram empregados 35 artigos, os quais descreveram sobre as quatro espécies de AVL ou sobre uma, duas ou três espécies, e consistiram em trabalhos de revisão ou voltados à pesquisa científica.

\section{Aspectos gerais das Amebas De Vida Livre (AVL)}

As Amebas de Vida Livre (AVL) são consideradas parasitos facultativos, pois se encontram em transição para a vida parasitária, tendo sido o potencial patogênico com doença grave no SNC, infecções na pele, órgãos internos e olhos de indivíduos imunocompetentes e imunocomprometidos demonstrado para Naegleria fowleri, Balamuthia mandrillaris, Sappinia pedata e algumas espécies de Acanthamoeba spp. (BARRAT et al., 2010; VISVESVARA, 2010; WALOCHNIK, 2014).

As AVL possuem duas formas evolutivas, o trofozoíto ou forma ativa, que se alimenta, movimenta e reproduz, e, o cisto ou forma quiescente, responsável pela resistência ambiental. Ambas as formas evolutivas podem ser adquiridas através do contato com os olhos, com as vias nasais ou com lesões na pele, mas somente os trofozoítos podem gerar 
danos às células e tecidos do hospedeiro vertebrado (CALIXTO et al., 2014; NIYYATI; LASGERDI; LORENZO-MORALES, 2015).

A forma cística pode ser constituída de dupla ou tripla parede celular, que confere elevada resistência a variações de temperatura, $\mathrm{pH}$, diversos agentes físicos e químicos como: cloração, óxido de deutério, irradiação ultravioleta, liofilização, congelamento e diversas drogas terapêuticas, dentre outros. Mas, podem ser sensíveis a autoclavação e ao óxido de etileno (THOMAS et al., 2010; DUPUY et al., 2011).

Diferentes meios de cultura podem ser empregados no cultivo das AVL, sendo o ágar não nutriente recoberto com Enterobacter spp., Escherichia coli e Klebsiella pneumoniae, o ágar soja 1,5\% e o meio líquido Peptone-Yeast-Glucose (PYG) os mais utilizados. Contudo, essas culturas são pouco realizadas nos laboratórios de análises clínicas (GARG, 2010; FEIZ HADDAD et al., 2019).

Até o advento da biologia molecular a diferenciação das espécies de AVL era realizada por meio das características morfológicas dos cistos e/ou trofozoítos tendo sido a classificação morfológica dos cistos de Acanthamoeba spp. de Pussard e Pons bastante empregada. No entanto, essa diferenciação é bastante complexa devido ao elevado pleomorfismo das diferentes espécies de AVL sendo difícil de ser executada até mesmo por observadores experientes (MAHMOUDI et. al., 2012; DELAFONT, et al., 2019; SAMBALOUAKA et al., 2019).

Para a correta identificação das espécies de AVL devem-se utilizar diferentes técnicas como: testes bioquímicos, de termotolerância, osmolaridade, exflagelação, métodos imunológicos, e principalmente, as ferramentas de biologia molecular como a Polymerase Chain Reaction (PCR) e o sequenciamento de DNA que permitem a identificação genética dessas amebas (NIYYATI; LASGERDI; LORENZO-MORALES, 2015; DELAFONT, et al., 2019).

O desenvolvimento de novas técnicas de identificação das AVL, mais sensíveis e específicas, tem demonstrado a necessidade de revisão a cerca da taxonomia e espécies das amebas descritas. Tem sido sugerida a abolição do sistema de classificação em reino, filo, classe, ordem e família. Mas, essa proposta ainda não é consenso (WALOCHNIK, 2014; NIYYATI; LASGERDI; LORENZO-MORALES, 2015).

\section{Acanthamoeba spp. e suas diversas formas de infecção}

A primeira descrição sobre a patogenicidade das AVL ocorreu em 1958 quando amebas com características morfológicas de Acanthamoeba spp., contaminantes de culturas 
do vírus pólio, conduziram modelos animais ao óbito uma semana após a inoculação. Desde então várias espécies desse gênero têm se configurado como importantes agentes etiológicos de ceratite amebiana em indivíduos imunocompetentes, e, Encefalite Amebiana Granulomatosa (EAG), infecções na pele, sinusóides e órgãos internos (fígado e pulmões) em indivíduos imunocomprometidos, sendo esse a AVL mais estudada (WALOCHNIK, 2014; PINNA et al., 2017).

As espécies de Acanthamoeba spp. foram inicialmente classificadas com base na presença de acantapódios nos trofozoítos, e, no tamanho e morfologia dos cistos de dupla parede celular. A introdução da biologia molecular permitiu que essas espécies fossem agrupadas em subtipos ou genótipos, denominados T1 a T12. Recentemente, aproximadamente outros cinco genótipos de Acanthamoeba spp. foram descritos. Mas, o genótipo T4 é o principal associado com infecções oculares e não oculares. Além disso, os genótipos T1, T10 e T12 também são descritos em infecções não oculares (MAHMOUDI et. al., 2012; ÜSTÜNTÜRK-ONAN; WALOCHNIK, 2018; SAMBA-LOUAKA et al., 2019).

Através de serinas proteases a Acanthamoeba spp. promove a degradação de colágeno tipo I, III e IV, elastina, fibronectina, plasminogênio, albumina e hemoglobina, enquanto, a partir de metaloproteases degrada colágeno tipo I e III, elastina e plasminogênio. Acanthamoeba culbertsoni também foi capaz de induzir apoptose em algumas células, a qual parece dispensar o contato celular. Também tem sido proposta a ação paracelular de Acanthamoeba spp., pois essa ameba induziu alteração da integridade celular in vitro (ELSHEIKHA; KHAN, 2010; KANESHIRO et al., 2011; WALOCHNIK, 2014).

A cultura tem sido empregada como método padrão-ouro no diagnóstico, mas o ideal é associá-la a técnicas de identificação genética como a PCR e o sequenciamento de DNA. Considerando as dificuldades enfrentadas no tratamento, o diagnóstico adequado e precoce pode favorecer o bom prognóstico, pois permite uma rápida intervenção terapêutica, ainda que até o momento não haja um protocolo padrão (PINNA et al., 2017; CARRIJOCARVALHO et al., 2019; BAIG, 2019).

\section{Encefalite Amebiana Granulomatosa (EAG) por Acanthamoeba spp.}

Em 1965 essa ameba foi definida como o agente de meningoencefalite altamente agressiva na Austrália, mas, na realidade os casos descritos decorreram de infecção por $N$. fowleri. Assim, o primeiro caso de infecção no SNC por Acanthamoeba spp. foi descrito somente após sete anos. Desde então, cerca de 150 casos de EAG por Acanthamoeba spp. 
foram descritos, dos quais somente 7\% cursaram com bom prognóstico (WALOCHNIK, 2014).

Encefalite Amebiana Granulomatosa (EAG) por Acanthamoeba spp. é insidiosa e grave manifestando-se cronicamente através de sintomas pouco específicos como cefaleia, rigidez de nuca e alterações de comportamento que conduzem ao coma e a morte. A infecção no SNC é resultado da migração da ameba por via nasal com passagem pela lâmina crivosa do etmoide por meio do nervo olfatório, por contato com a pele ou por disseminação sanguínea (VISVESVARA, 2010; FEIZ HADDAD et al., 2019).

No parênquima cerebral a Acanthamoeba spp. faz com que o sistema imunológico desenvolva um granuloma composto por células da microglia, macrófagos e linfócitos produtores de citocinas pró-inflamatórias. Essa encefalite pode ser confundida com aquela provocada por Toxoplasma gondii e Trypanosoma cruzi, dificultando a adoção de tratamento específico. Este, geralmente inclui a associação de pentamidinas e sulfadiazinas, apesar de não ser uma conduta padrão (BAIG, 2019).

\section{Ceratite Amebiana por Acanthamoeba spp.}

Os primeiros casos de ceratite por Acanthamoeba foram descritos em 1973 nos EUA e na Inglaterra. A partir daí casos esporádicos foram relatados em diferentes regiões do mundo, que aumentaram significamente após o uso indiscriminado de lentes de contato na década de 1980. As lentes de contato do tipo gelatinoso parecem facilitar a infecção devido a sua porosidade e por serem utilizadas diariamente em longo prazo (PINNA et al., 2017).

Nos países desenvolvidos a ceratite por Acanthamoeba spp. pode atingir até $90 \%$ dos usuários de lentes de contato devido ao hábito de não retirar as lentes para dormir e/ou pela má higienização das mesmas, com utilização de água de torneira e outros compostos esterilizantes de baixa eficiência. Nos EUA a prevalência é de 1,83 casos por milhão de habitantes e no Reino Unido de 18,52 (FEIZ HADDAD et al., 2019).

No Brasil, os primeiros casos foram descritos em 1988, mas, os relatos são escassos e se concentram em algumas regiões. Nos países onde o uso de lentes de contato é baixo, a ceratite por Acanthamoeba spp. se relaciona principalmente ao trauma, atividades agrícolas e exposição ao solo, lama ou água contaminada. Esses fatores correspondem de três a $15 \%$ dos casos de ceratite amebiana nos países desenvolvidos (LARES-JIMÉNEZ et al., 2018).

Diversas espécies de Acanthamoeba como Acanthamoeba poliphaga A. castellani e A. culbertsoni se associam a ceratite amebiana. Dentre os genótipos, o T4 é o mais comum, embora T2, T3, T5, T6, T10, T11, T15 e T17 também sejam relatados com menos frequência. 
Contudo, T7, T8 e T9 ainda não foram associados à infecção nos olhos (NIYYATI et al., 2010).

A ceratite por Acanthamoeba spp. geralmente ocorre unilateralmente e manifesta-se com severa inflamação ocular revelando lacrimejamento, dor, fotofobia, visão turva e diminuição da acuidade visual com quadros de melhora e piora que podem levar à cegueira mesmo após ceratoplastia (FEIZ HADDAD et al., 2019).

A inespecificidade dos sintomas e ocorrência de infiltrado em anel fazem com que a ceratite amebiana por seja confundida com aquela provocada por fungos, vírus ou pelo uso abusivo de anestésico tópico. O ideal é investigar a ceratite amebiana por Acanthamoeba spp. em todos os pacientes que apresentarem úlcera infecciosa, especialmente em usuários de lentes de contato (GARG, 2010).

Acanthamoeba spp. é altamente resistente às soluções desinfetantes de lentes de contato. Essas soluções têm se associado à indução de pseudocistos ou cistos incompletos, os quais apesar de possuírem uma única parede celular conseguem manter a viabilidade dos trofozoítos. Uma proteína transmembrana ligada a manose (MBP) parece ser a principal envolvida na adesão da ameba a córnea. Essa ligação favorece a produção e secreção de metaloproteinases dependentes de contato, e serinas proteinases não dependentes de contato, com efeito, citopático e de evasão ao sistema imunológico (ELSHEIKHA; KHAN, 2010; KANESHIRO et al., 2011; WALOCHNIK, 2014).

A dupla parede e presença de celulose na parede interna dos cistos configuram elevada resistência às drogas terapêuticas. Por isso, associações medicamentosas, como biguanidas e diaminas, não garantem o sucesso do tratamento. Em estudo recente o antibiótico catiônico esteróide (CSA-13) revelou média citotoxicidade em trofozoítos de A. castellanii in vitro. Outros gêneros: Naegleria, Hartmanella, Paravahlkampfia e Vahlkampfia já foram isoladas dos olhos, embora mais raramente (ABEDKHOJASTEH et al., 2013; CALIXTO et al., 2014; BAIG, 2019).

\section{Ceratite amebiana por Hartmannella spp. e Vahlkampfia spp.}

Em 1992, Hartmanella spp. e Vahlkampfia spp. foram isoladas de amostras oculares. Essas amebas também parecem estar associadas à utilização de lentes de contato, tendo sido descritas infecções mistas entre Acanthamoeba spp. e Vahlkampfia spp., e, Hartmannella spp. e Vahlkampfia spp. (NIYYATI et al., 2010; ABEDKHOJASTEH et al., 2013; PINNA et al., 2017). 
A distribuição ambiental é ampla, mas o potencial patogênico não está bem esclarecido, alguns estudos apontaram a participação apenas como contaminantes, em outros essas AVL foram identificadas no interior de ceratinócitos e produziram efeitos citopáticos semelhantes a A. castellanii in vitro (BARRAT et al., 2010; ABEDKHOJASTEH et al., 2013).

Embora esteja associada principalmente a infecções oculares, Hartmanella vermiformis já foi isolada de amostra de Líquido Cefalorraquidiano (LCR) de um paciente com meningoencefalite e broncopneumonia. Essas AVL são mais sensíveis à ação de biguanidas e propamidina do que Acanthamoeba spp. (BARRAT et al., 2010; BAIG, 2019).

\section{Meningoencefalite Amebiana Primária (MAP) por Naegleria fowleri}

Os primeiros casos de meningoencefalite amebiana primária (MAP) por Naegleria fowleri foram descritos em 1965 quando quatro australianos previamente saudáveis vieram a óbito após sete dias de infecção. Um ano depois, outros três casos foram descritos nos EUA e todos eles estiveram associados à atividade aquática A maioria das infecções causadas por $N$. fowleri é descrita nesse país (VISVESVARA, 2010; NIYYATI et al., 2015).

Pouco mais de 200 casos foram relatados e a taxa de mortalidade se mantém ao redor de 95\%, tendo ocorrido também na Checoslováquia, Austrália, México, Nova Zelândia, Nigéria, França, Grã Bretanha e Índia. No Brasil, o primeiro caso de MAP por N. fowleri foi descrito em 1972 no Rio de Janeiro, mas a exemplo de Acanthamoeba spp. esses relatos são escassos e limitados a descrições em poeira e água (LARES-JIMÉNEZ et al., 2018).

Existem mais de 30 espécies de Naegleria spp., mas somente $N$. fowleri é patogênica para os seres humanos. Essa espécie possui tropismo por temperaturas elevadas, sendo encontrada principalmente em ambientes com águas termais incluindo água doce, lagos, água mineral e resorts. Por isso, é importante considerar às atividades recreativas realizadas há cerca de duas semanas na anamnese clínica, especialmente em crianças, adolescentes e jovens adultos imunocompetentes, pois a MAP se manifesta em uma ou duas semanas após a recreação aquática (HEGGIE, 2010; WALOCHNIK, 2014; LARES-JIMÉNEZ et al., 2018).

Mais raramente, os casos de infecção por $N$. fowleri também se relacionam com a inalação de cistos presentes em poeira. Outra característica importante é a presença de três formas evolutivas em seu ciclo biológico: o trofozoíto ameboide, o cisto esférico com dupla parede celular e o trofozoíto biflagelado. O trofozoíto biflagelado possui a forma de pêra, não se alimenta ou reproduz e ocorre apenas em ambientes aquáticos. Em cultura podem ser 
revelados por meio da prova de exflagelação, na qual se incuba a ameba em água destilada a $37^{\circ} \mathrm{C}$ por quatro horas (WALOCHNIK, 2014; LARES-JIMÉNEZ et al., 2018).

A $N$. fowleri possui tropismo por bainha de mielina e atinge o SNC ao entrar em contato com as narinas, de onde migra para o nervo olfatório cruzando a área cribiforme, alcançando, por fim, o parênquima cerebral por meio do bulbo olfatório, iniciando a MAP, num mecanismo semelhante à EAG por Acanthamoeba spp. O período de incubação varia de uma a duas semanas do contato prévio, mas a infecção pode se iniciar com apenas 24 horas após contato (FEIZ HADDAD et al., 2019).

No parênquima cerebral é instalado um processo inflamatório intenso que gera necrose e hemorragia devido à utilização de células nervosas como nutriente pela ameba. As lesões no parênquima cerebral podem alcançar a periferia revelando trofozoítos de $N$. fowleri no líquido cefalorraquidiano (Líquor ou LCR). O diagnóstico de MAP pode ser realizado a partir de punção do líquor, o qual não deve ser refrigerado visando-se preservar a movimentação dos trofozoítos ameboides no exame a fresco. Também podem ser realizadas a coloração de Wright's, Giemsa e Hematoxilina-Eosina e realizada a cultura, o teste de exflagelação e a PCR. Contudo, é importante ressaltar que o crescimento em cultura de $N$. fowleri e de cepas não patogênicas de Naegleria spp. sob mesmas condições é relativamente difícil e variável conforme o meio de cultura adotado (VISVESVARA, 2010; WALOCHNIK, 2014).

A MAP por $N$. fowleri é uma etiologia aguda e fulminante manifestando-se inicialmente com febre entre $38^{\circ} \mathrm{C}$ e $41^{\circ} \mathrm{C}$, cefaleia bifrontal ou bitemporal e, em alguns casos, rinite. Logo após ocorrem outros sintomas como: rigidez de nuca com sinais de Kernig e Brudzinski positivos, letargia, confusão mental, alterações no comportamento, diplopia, convulsões e coma que sem tratamento conduzem à morte em aproximadamente sete dias. Não raramente, a MAP é confundida com meningite bacteriana por causa da inespecificidade dos sintomas e rápido curso evolutivo da doença (HEGGIE, 2010; BAIG, 2019).

Exames de imagem revelam as lesões no SNC, mas essas são inespecíficas e não permitem diferenciar a etiologia da MAP por N. fowleri daquelas provocadas por outros microrganismos. O método de ELISA também pode ser empregado e reconhece um epítopo glicosilado de N. fowleri permitindo a sua diferenciação de outras AVL ou mesmo de outras espécies de Naegleria spp. PCR em tempo real e imunofluorescência podem ser utilizadas para identificar $N$. fowleri em diferentes amostras (NIYYATI et al., 2015).

A PCR empregando os iniciadores ITS1/ITS2 têm identificado não apenas o gênero Naegleria spp. como também os gêneros Willaertia spp., Vahlkampfia spp. e Hartmanella spp., permitindo a detecção de vários microrganismos em um único experimento. Com 
relação ao tratamento, $N$. fowleri, ao contrário das demais AVL, é sensível a anfotericina B, pode ser administrada pelas vias intratecal ou intravenosa, ou associada ao miconazol, a rifamicina e a azitromicina durante 10 dias (BAIG, 2019; FEIZ HADDAD et al., 2019).

\section{Encefalite Amebiana Granulomatosa por Balamuthia mandrillaris}

A patogenicidade da B. mandrillaris foi demonstrada em 1985, ao ter sido identificada como o agente causador de Encefalite Amebiana Granulomatosa (EAG) em uma macaca mandril que foi responsável pela sua nomenclatura. A infecção é comum em animais. Em 1993, foi detectado o primeiro caso humano, e diferentemente da infecção por Acanthamoeba spp., esta pode ser oportunista ou não. Entre os imunocompetentes as crianças são as mais afetadas (HODGE et al., 2011; SIDDIQUI; KHAN, 2015).

Em indivíduos com algum grau de imunodeficiência, como portadores do vírus HIV/SIDA, doentes crônicos, transplantados e/ ou em uso de quimioterápicos, a $B$. mandrillaris também se associa com infecções na pele e nos sinusóides. Até o momento cerca de 100 casos foram descritos nos EUA, República Tcheca, Japão, Austrália, México, Argentina, Venezuela, Chile, Peru e Brasil. Assim como a infecção por N. fowleri a taxa de mortalidade em EAG por B. mandrillaris é maior que 95\% (COPE et al., 2016; YAMANOUCHI et al., 2018).

A fonte de contaminação por B. mandrillaris não está totalmente elucidada, essa ameba parece ser encontrada preferencialmente no solo, embora em alguns casos possa se relacionar à natação. Possui duas formas evolutivas: o trofozoíto e o cisto. O trofozoíto possui vários pseudópodes pontiagudos que o deixa em "forma de galho" ou semelhantes a uma aranha. E o cisto tem uma parede celular a mais, o mesocisto que se localiza entre o endocisto e ectocisto. Em cultura de hepatócitos foram observados trofozoítos com um, dois e vários núcleos, mas é convencional dizer que essa ameba possui apenas um núcleo (DUNNEBACKE, 2010; WALOCHNIK, 2014).

A infecção pode ser adquirida a partir das vias aéreas superiores, por lesão cutânea prévia ou por disseminação sanguínea, assim como os mecanismos desencadeados por $N$. fowleri e Acanthamoeba spp., respectivamente. Em modelos experimentais, também foi descrita a infecção por via oral, a qual gerou alterações no estômago, intestino delgado e grosso, fígado, pulmões e rins. Em outros estudos, a passagem pelo sistema gastrointestinal diminuiu o potencial patogênico da ameba sem efeito patogênico no hospedeiro (WALOCHNIK, 2014; SIDDIQUI; KHAN, 2015). 
A EAG por B. mandrillaris manifesta-se cronicamente podendo levar até dois anos após o contato prévio para se desenvolver e se caracteriza por hemorragia e necrose similar àquela observada na EAG por Acanthamoeba spp. Os sintomas incluem febre, dor de cabeça, lesão na pele, náuseas, rigidez de nuca, sonolência, confusão mental, coma e morte. Em muitos casos se associa à infecção na pele (SIDDIQUI; KHAN, 2015; COPE et al., 2016).

A inespecificidade dos sintomas faz com que a infecção seja confundida com outras encefalites como a EAG por Acanthamoeba spp., a neurotoxoplasmose, a Doença de Chagas neurológica, a paracoccidioidomicose, a hanseníase, o lúpus, a leishmaniose, a esporotricose, a granulomatose de Wegener e até mesmo com o câncer (COPE et al., 2016; YAMANOUCHI et al., 2018).

O diagnóstico é difícil sendo realizado pela observação da ameba em biópsias ou autópsias em conjunto com técnicas imunohistoquímicas, colorações fluorescentes com anticorpos específicos ou cultura celular. A cultura é relativamente difícil, pois $B$. mandrilaris, diferentemente das demais AVL, não utiliza bactérias como fonte alimentar, exigindo meios de cultura celular axênicos e rigorosamente e suplementados para o seu crescimento. Também se desenvolve melhor em cultura de células endoteliais microvasculares de cérebro do que em fibroblastos de rim de macaco (SIDDIQUI; KHAN, 2015; LONG et al., 2018).

Os exames de imagem são inconclusivos sendo comum visualizar lesão focal cística, edema e hidrocefalia, os quais também observados em outros tipos de infecções neurológicas. Também podem ser utilizados: ELISA, citometria de fluxo e PCR, essa ameba não possui variações na sequência SSU do rDNA e a variação no DNA mitocondrial é relativamente baixa, podendo ser detectada e diferenciada de Acanthamoeba spp. por meio dos iniciadores dirigidos para a região 16S do RNA ribossômico (DELAFONT, et al., 2019; SAMBALOUAKA et al., 2019).

O tratamento é difícil e muitas vezes as associações medicamentosas são necessárias. Geralmente são empregados a pentamidina, a azitromicina, a anfotericina B e o fluconazol (VISVESVARA, 2010; BAIG, 2019).

\section{Encefalite Amebiana Granulomatosa por Sappinia pedata}

Um único caso de Encefalite Amebiana Granulomatosa (EAG) por Sappinia diploidea foi descrito até o momento, existindo discussão relacionada à nomenclatura dessa ameba que também é denominada Sappinia pedata. A infecção parece ter se estabelecido via trato respiratório com acometimento dos sinusóides. O prognóstico favorável foi revelado após 
adoção de terapia com azitromicina, pentamidina, itraconazol e flutisonina (VISVESVARA, 2010).

Essa ameba possui trofozoíto e cisto binucleado e é isolada preferencialmente do solo, fezes de alce e búfalo, plantas em decaimento e água fresca. Mas, pouco é sabido sobre o período de incubação, forma de contaminação e patogenicidade em humanos e animais (LARES-JIMÉNEZ et al., 2018).

\section{A importância médica de outras AVL}

Outras AVL como a Vanella spp., a Echinamoebae spp., a Willaertia spp. e a Saccamoebae spp. não foram associadas a infecção em humanos até o momento, mas adquirem importância médica pela veiculação de bactérias, vírus, fungos e protozoários patogênicos, pois podem estabelecer endossimbiotismo e assim gerar infecções relacionadas a assistência em saúde (IRAS) (THOMAS et al., 2010; DUPUY et al., 2011; LONG et al., 2018).

Essa interação é resultado da adaptação desses patógenos a reciclagem natural da água e solo. Diversos deles desenvolveram mecanismos de penetração ativa nas AVL e evadem seus sistemas de digestão sendo veiculados no meio ambiente. Além disso, a relação estabelecida favorece a multiplicação desses patógenos no interior das AVL podendo gerar aumento de sua virulência e resistência, mas não é benéfico para a AVL (PATERSON et al., 2011; LARES-JIMÉNEZ et al., 2018).

Dentre as associações existentes, as mais estudadas são aquelas com Legionella pneupmophila, Mycobacterium leprae, Pseudomonas aerugynosa, Cryptosporidium parvum e Cryptococcus neoformans. O estudo de endossimbiontes é bastante importante, pois além de permitir se conhecer as interações estabelecidas entre as AVL e diferentes patógenos, pode também contribuir com a otimização de culturas laboratoriais (SAMBA-LOUAKA et al., 2018).

Com isso, as AVL podem interagir diretamente com os seres humanos e animais produzindo infecções severas no SNC, na pele, em órgãos internos e olhos, e indiretamente, veiculando bactérias, vírus, fungos e protozoários patogênicos (VISVESVARA, 2010; THOMAS et al., 2010; LONG et al., 2018).

\section{Conclusão}

Embora as infecções pelas AVL, mais especificamente por Acanthamoeba spp., Naegleria fowleri, Balamuthia mandrillaris e Sappinia pedata, sejam tidas como raras, elas se 
mostram altamente agressivas cursando com elevado grau de morbimortalidade já que há dificuldades em se estabelecer o diagnóstico e tratamento eficaz. Além disso, essas amebas podem carrear patógenos e contribuir com a ocorrência de infecções relacionadas à assistência em saúde (IRAS), sendo pouco divulgadas na sociedade o que contribui com o baixo relato dos casos ou casos de subnotificação.

\section{REFERÊNCIAS}

ABEDKHOJASTEH, $H$. et al. First Report of Hartmannella keratitis in a Cosmetic Soft Contact Lens Wearer in Iran. Iran J Parasitol, v. 8, n. 3, p. 481-485, 2013. Disponível em: https://www.ncbi.nlm.nih.gov/pmc/articles/PMC3887252/. Acesso em 09 jul. 2010.

BAIG, A.M. Innovative Methodology in the Discovery of Novel Drug Targets in the FreeLiving Amoebae. Curr Drug Targets, v. 20, n. 1, p. 60-69, 2019. doi: 10.2174/1389450119666180426100452. Disponível em: https://pubmed.ncbi.nlm.nih.gov/29697029/. Acesso em: 06 jul. 2020.

BALCZUN, C.; SCHEID, P.L. Free-Living Amoebae as Hosts for and Vectors of Intracellular Microorganisms with Public Health Significance. Viruses MDPI, v. 9, n. 65, doi:10.3390/v9040065, 2017. Disponível em: https://www.mdpi.com/1999-4915/9/4/65. Acesso em: 06 jul. 2020.

BARRAT, J.L. et al. Importance of nonenteric protozoan infections in immunocompromised people. Clinical Microbiology Review, v. 23, n. 4, p. 795-836, 2010. Disponível em: https://www.ncbi.nlm.nih.gov/pmc/articles/PMC2952979/pdf/0001-10.pdf. Acesso em: 06 jul. 2020.

CALIXTO, P.H.M. et al. Aspectos biológicos das principais amebas de vida-livre de importância médica. Biota Amazônia, v. 4, n. 2, p. 124-129, 2014. Disponível em: http://dx.doi.org/10.18561/2179-5746/biotaamazonia.v4n2p124-129. Acesso em: 01 jun. 2020.

CARRIJO-CARVALHO, L.C. et al. Therapeutic Agents and Biocides for Ocular Infections by Free-Living Amoebae of Acanthamoeba Genus. Surv Ophthalmol, v. 62, n. 2, p. 203-218, 2017. Disponível em: https://www.surveyophthalmol.com/article/S0039-6257(16)300182/fulltext. Acesso em: 09 jul. 2020.

COPE, J.R. et al. The Epidemiology and Clinical Features of Balamuthia mandrillaris Disease in the United States, 1974-2016. Clin Infect Dis, v. 68, n. 11, p. 1815-1822, 2019. Disponível em: https://pubmed.ncbi.nlm.nih.gov/30239654/. Acesso em: 09 jul. 2020. 
DELAFONT, V. et al. Targeted Metagenomics of Microbial Diversity in Free-Living Amoebae and Water Samples. Methods Mol Biol, v. 1921, p. 421-428, 2019. doi: 10.1007/978-1-4939-9048-1_26. Disponível em: https://pubmed.ncbi.nlm.nih.gov/30694507/. Acesso em: 06 jul. 2020.

DUNNEBACKE, T.H. Balamuthia mandrillaris: The multiple nuclei of Balamuthia amebas; their location, activity, and site of development. Experimental Parasitology, v. 126, p. 1421, 2010. Disponível em: https://www.sciencedirect.com/science/article/abs/pii/S0014489409003002. Acesso em: 07 jul. 2020.

DUPUY, M. et al. Efficiency of water disinfectants against Legionella pneumophila and Acanthamoeba. Water Research, v. 45, p. 1087-1094, 2011. Disponível em: https://www.sciencedirect.com/science/article/abs/pii/S0043135410007207. Acesso em: 07 jul. 2020.

ELSHEIKHA, H.M.; KHAN, N.A. Protozoa traversal of the blood-brain barrier to invade the central nervous system. FEMS Microbiol Rev, v. 34, p. 532-553, 2010. Disponível em: https://academic.oup.com/femsre/article/34/4/532/540867. Acesso em: 07 jul. 2020.

FARRA, A. et al. Free-living Amoebae Isolated in the Central African Republic: Epidemiological and Molecular Aspects. Pan Afr Med J, v. 26, n. 57, 2017. Disponível em: https://www.ncbi.nlm.nih.gov/pmc/articles/PMC5398892/pdf/PAMJ-26-57.pdf. Acesso em: 06 jul. 2020.

FEIZ HADDAD, M.H. et al. Molecular Identification of Free-Living Amoebae (Naegleria spp., Acanthamoeba spp. and Vermamoeba spp.) Isolated from Un-improved Hot Springs, Guilan Province, Northern Iran. Iran J Parasitol, v. 14, n. 4, p. 584-591, 2019. Disponível em: https://www.ncbi.nlm.nih.gov/pmc/articles/PMC7028243/. Acesso em: 09 jul. 2020.

GARG, P. Diagnosis of microbial keratitis. Br J Ophthalmol, v. 94, n. 8, p. 961-962, 2010. Disponível em:

https://www.researchgate.net/publication/45461234_Diagnosis_of_microbial_keratitis. Acesso em: 07 jul. 2020.

HEGGIE, T.W. Swimming with death: Naegleria fowleri infections in recreational Waters. Travel Medicine and Infectious Disease, v. 8, n. 4, p. 201-206, 2010. Disponível em: https://www.sciencedirect.com/science/article/abs/pii/S1477893910000980?via\%3Dihub. Acesso em: 09 mai. 2020.

HODGE, P.J. et al. Another case of canine amoebic meningoencephalitis - the challenges of reaching a rapid diagnosis. Parasitol Res, v. 108, p. 1069-1073, 2011. Disponível em: https://link.springer.com/article/10.1007/s00436-010-2197-z. Acesso em: 09 jul. 2020. 
KANESHIRO, E.S. et al. Highlights and Summaries of the 11th International Workshops on Opportunistic Protists. J. Eukaryot. Microbiol., v. 58, n. 1, p. 1-6, 2011. Disponível em:https://onlinelibrary.wiley.com/doi/abs/10.1111/j.1550-7408.2010.00515.x. Acesso em: 07 jul. 2020.

KRÓL-TURMIŃSKA, K.; OLENDER, A. Human infections caused by free-living amoebae. Annals of Agricultural and Environmental Medicine, v. 24, n. 2, 2017. Disponível em: http://www.aaem.pl/Human-infections-caused-by-free-living-amoebae, 72498,0,2.html. Acesso em: 06 jul. 2020.

LARES-JIMÉNEZ, L.F. et. Potentially Pathogenic Genera of Free-Living Amoebae Coexisting in a Thermal Spring. Exp Parasitol, v. 195, p. 54-58, 2018. Disponível em: https://www.sciencedirect.com/science/article/abs/pii/S0014489418303709?via\%3Dihub. Acesso em: 06 jul. 2020.

LONG, J.J. et al. Interactions of Free-Living Amoebae With Rice Bacterial Pathogens Xanthomonas Oryzae Pathovars Oryzae and Oryzicola. PLoS One, v. 13, n. 8, p. e0202941, 2018. Disponível em:

https://journals.plos.org/plosone/article/file?id=10.1371/journal.pone. $0202941 \&$ type=printabl e. Acesso em: 06 jul. 2020.

MAHMOUDI, M.R. et al. Isolation of Acanthamoeba species in surface waters of Gilan province-north of Iran. Parasitol Res, v. 110, p. 473-477, 2012. Disponível:

https://link.springer.com/article/10.1007/s00436-011-2530-1. Acesso em: 07 jul. 2020.

MARCIANO-CABRAL, F.; JAMERSON, M.; KANESHIRO, E.S. Free-living amoebae, Legionella and Mycobacterium in tap water supplied by a municipal drinking water utility in the USA. Journal of Water and Health, v.8, p. 71- 82, 2010. Disponível em:

https://iwaponline.com/jwh/article/8/1/71/1895/Free-living-amoebae-Legionella-andMycobacterium. Acesso em: 01 jun. 2020.

NIYYATI, M. First report of a mixed infection due to Acanthamoeba genotype T3and Vahlkampfia in a cosmetic soft contact lens wearer in Iran. Experimental Parasitology, v.126, p. 89-90, 2010. Disponível em: https://www.sciencedirect.com/science/article/abs/pii/S0014489409002975. Acesso em: 07 jul. 2020.

NIYYATI, M.; LASGERDI, Z.; LORENZO-MORALES, J. Detection and Molecular Characterization of Potentially Pathogenic Free-living Amoebae from Water Sources in Kish Island, Southern Iran. Microbiol Insights, v. 8, s. 1, p. 1-6, 2015. Disponível em: https://www.ncbi.nlm.nih.gov/pmc/articles/PMC4399642/. Acesso em: 09 jul. 2020.

NIYYATI, M. et al. Morphological and Molecular Survey of Naegleria spp. In Water Bodies Used for Recreational Purposes in Rasht city, Northern Iran. Iran J Parasitol, v. 10, n. 4, p.523-529, 2015. Disponível em: 
https://www.ncbi.nlm.nih.gov/pmc/articles/PMC4724827/pdf/IJPA-10-523.pdf. Acesso em: 09 jul. 2020.

PATERSON, G.N. et al. Is Acanthamoeba pathogenicity associated with intracellular bacteria? Experimental Parasitology, v. 129, p 207-210, 2011. Disponível em: https://www.sciencedirect.com/science/article/abs/pii/S0014489411002049. Acesso em: 01 jun. 2020.

PINNA, A. et al. Free-Living Amoebae Keratitis. Cornea, v. 36, n. 7, p. 785-790, 2017. Disponível em:

https://journals.1ww.com/corneajrnl/Abstract/2017/07000/Free_Living_Amoebae_Keratitis.6. aspx. Acesso em: 06 jul. 2020.

SAMBA-LOUAKA, A. et al. Environmental Mycobacterium avium Subsp. paratuberculosis Hosted by Free-Living Amoebae. Front Cell Infect Microbiol, v. 9, p. 8:28, 2018. Disponível em: https://www.ncbi.nlm.nih.gov/pmc/articles/PMC5811464/pdf/fcimb-0800028.pdf. Acesso em: 06 jul. 2020.

SAMBA-LOUAKA, A. et al. Free-living Amoebae and Squatters in the Wild: Ecological and Molecular Features. FEMS Microbiol Ver, v. 43, n. 4, p. 415-434, 2019. Disponível em: https://pubmed.ncbi.nlm.nih.gov/31049565/. Acessom em: 06 jul. 2020.

SIDDIQUI, R.; KHAN, N.A. Balamuthia mandrillaris: Morphology, biology, and virulence. Trop Parasitol, v. 5, n. 1, p. 15-22, 2015. Disponível em: https://www.ncbi.nlm.nih.gov/pmc/articles/PMC4326988/?report=reader. Acesso em: 09 jul. 2020.

THOMAS, V. et al. Free-living amoebae and their intracellular pathogenic microorganisms: risks for water quality. FEMS Microbiology Reviews, v. 34, p. 231-259, 2010. Disponível em: https://pubmed.ncbi.nlm.nih.gov/19744244/. Acesso em: 01jun. 2020.

ÜSTÜNTÜRK-ONAN, M.; WALOCHNIK, J. Identification of Free-Living Amoebae Isolated From Tap Water in Istanbul, Turkey. Exp Parasitol, v. 195, p. 34-37, 2018. Disponível em: https://www.sciencedirect.com/science/article/abs/pii/S0014489418301413?via\%3Dihub. Acesso em: 06 jul. 2020.

VISVESVARA, G.S. Amebic meningoencephalitides and keratitis: challenges in diagnosis and treatment. Current Opinion in Infectious Diseases, v. 23, p. 590-594, 2010. Disponível em: https://pubmed.ncbi.nlm.nih.gov/20802332/. Acesso em: 07 jul. 2020.

WALOCHNIK, J. Free-living Amoebae: Ecology, Phylogeny, Pathogenicity, Susceptibility and Interactions With Other Cells. Exp Parasitol, v. 145, s. S1, 2014. Disponível em: https://pubmed.ncbi.nlm.nih.gov/25448291/. Acesso em: 06 jul. 2020. 
YAMANOUCHI, K. et al. First report of the isolation of Balamuthia mandrillaris in the northern region of Japan. Parasitology Research, v. 117, p. 2895-2900, 2018. Disponível em: https://link.springer.com/content/pdf/10.1007/s00436-018-5980-x.pdf. Acesso em: 09 jul. 2020 . 